\title{
Replication of mini-F plasmids during the bacterial division cycle
}

\author{
J.D. Keasling ${ }^{(1)}$, B.O. Palsson ${ }^{(1)}$ and S. Cooper ${ }^{(2)(*)}$ \\ "'Department of Chemical Engineering, University of Michigan, Ann Arbor, MI 48109-2136 and \\ ${ }^{(2)}$ Department of Microbiology and Immunology, University of Michigan Medical School, Ann Arbor, \\ MI 48109-0620 (USA)
}

\begin{abstract}
SUMMARY
The cell-cycle replication patterns of two mini-F plasmids have been examined using the membrane-elution technique (to produce cells labelled at different times during the division cycle) and scintillation counting (for quantitative analysis of radioactivity incorporated into plasmid DNA). The mini-F plasmid pML31, which contains the oriV and oriS origins of replication, replicates in a cell-cycle-specific manner with a pattern and cellcycle timing similar to the parental F plasmid. The mini-F plasmid pMF21, deleted for the region containing the oriV origin of replication, replicates more randomly throughout the division cycle. These results suggest that the oriV origin of replication may be related to cell-cycle-specific replication of the $F$ plasmid.
\end{abstract}

:Key-words: Plasmid, Cell cycle, F plasmid, Replication; Origins, Escherichia coli.

\section{INTRODUCTION}

How does a low-copy-number plasmid replicate in concert with cell division to ensure stable inheritance of the plasmid to all descendant cells? Recently, it was shown that the F plasmid and the $P 1$ prophage replicate during a restricted portion of the Escherichia coli division cycle, at a time different fiom a minichromosome present in the same cel! (Keasling et al., 1991, 1992b). When the cell-cycle age of low-copy plasmid replication was determined over a range of growth rates, it was observed that the mechanism which regulates low-copy plasinid replica- tion is formally similar to the mechanism which regulates chromosome replication initiation, i.e. replication occurs when some cell property related to cell size or ceil mass reaches a constant value per origin. This mechanism ensures that there will be at least $t$ wo plasmids in the cell before division, allowing stable inheritance of plasmids. These experimental results have been supported by recent density-shift experiments demonstrating that F-plasmid replicates nonrandomly (Koppes, 1992). We now turn to the question of the molecular determinants responsible for this cell-cycle-specific replication pattern.

Submitted January 15, 1992, accepted June 12, 1992.

(*) Corresponding author. 
The molecular biology and enzymology of $F$ plasmid replication have been studied extensively (see Kline, 1985 and Lane, 198: , for comprehensive reviews). These studies have been facilitated in large part by the discovery that the f5 EcoR 1 fragment of the F plasmid replicates autonomously (Lovett and Helinski, 1976; Tinmis et al., 1975) and possesses many of the characteristics of the F plasmid: stability, incompatibility, and low copy number (Wada et al., 1987). Two origins of replication, oriV and oriS, have been identified on the mini-F plasmid pML31 constructed from the f5 EcoR1 fragment. A third origin of replication has been identified on the $77 E c o$ Rl fragment of the F plasmid. Replication from oriV on pML31 is bidirectional and predominant under most conditions when both oriV and oriS origins are present on the mini-F plasmid (Eichenlaub et al., 1977) and when all three origins are present on the native $F$ plasmid. However, it has been shown that replication from the oriS origin of replication on plasmid $\mathrm{nMF} 21$, which has been deleted for the 40.8 to $43.0-\mathrm{kb}$ region of the F plasmid containing the oriV origin, is unidirectional (Manis and Kline, 1978; Eichenlaub et al., 1981). How these two origins interact to initiate replication of the F plasmid primarily at ori $V$ is not fully understood.

In an attempt to determine the genetic locus responsible for cell-cycle-specific replication of the $F$ plasmid, we have investigated the replication patterns of these two mini-F plasmicis. We have used the membrane-elution technique to produce cells labelled at different times during the division cycle, and scintillation counting for quantitative analysis of radioactive plasmid DNA. Mini-F plasmid pML31 containing two origins of replication of the F plasmid (ori $\mathrm{V}$ and oriS) replicates in a cell-cycle-specific manner like the $F$ plasmid. The mini-F plasmid pMF21 deleted for one of the origins of replication (oriV) replicates more randomly throughout the division cycle. These results suggest that the oriV origin of replication may be responsible for, or contribute to, cell-cycle-specific replication of the $\mathrm{F}$ plasmid. This is the first identification of a putative genetic region associated with cell-cyclespecific replication of a plasmid.

\section{MATERIAI.S AND METHODS}

\section{Bacterial strains and plasmids}

The bacterial strain used for all experiments was Escherichia coli $\mathrm{B} / \mathrm{r}$ F44 (his ${ }^{-}$thr $^{-}$pro ${ }^{-}$) (compliments of A.C. Leonard). Plasmids pML31 (oriV oriS $\mathrm{kan}^{r}$ ) and pMF21 (oriS $\mathrm{kan}^{r}$ ) were transformed into separate F44 cells. These cells were then transformed with the minichromosome pAL70 (oriC $\mathrm{cam}^{r}$ ) (compliments of A.C. Leonard) and the mini-R6K plasmid pMF26 $\left(a m p^{\prime}\right)$ or the pBR322 plasmid $\left(a m p^{r}\left(e t^{\prime}\right)\right.$, so that each bacterial strain contained a plasmid with cell-cycle-specific replication (pAL70), a plasmid with cell-cycle-independent replication (pMF26 or pBR322), and a plasmid with unknown replication pattern (pML31 or pMF21). (The experiment described in figure 2 did not have pMF26 included.)

\section{Growth of bacteria}

C medium (Helmstetter and Cooper, 1968) was supplemented with histidine $(42 \mu \mathrm{g} / \mathrm{ml})$, proline $(46 \mu \mathrm{g} / \mathrm{ml})$, threonine $(46 \mu \mathrm{g} / \mathrm{ml})$ and succinate $(0.4 \%)$. The cells were grown for at least 6-9 generations in $100 \mathrm{ml}$ of medium at $37^{\circ} \mathrm{C}$.

\section{Membrane-elution technique}

Exponentially growing cells $(100 \mathrm{ml}, 1.0 \times$ $10^{8}$ cells $/ \mathrm{ml}$ ) were labelled with ${ }^{3} \mathrm{H}$-methyl thymidine $(60-80 \mathrm{Ci} / \mathrm{mmole}, 10 \mu \mathrm{Ci} / \mathrm{ml})$ for $5 \%$ of the doubling time $(5 \mathrm{~min})$ and filtered onto a nitrocellulose membrane at the end of the labelling period. The cells were washed with warm medium of the same composition containing cold thymidine $(100 \mu \mathrm{g} / \mathrm{ml})$. The membrane apparatus was inverted and newborn cells were eluted from the membrane with prewarmed $\mathrm{C}$ medium pumped at a rate of $2 \mathrm{ml} / \mathrm{min}$ in a $37^{\circ} \mathrm{C}$ incubator. Fractions were collected for an interval of time equivalent to the labelling period. Cell numbers were determined using a particle counter (Coulter Electronics, model $\mathrm{ZM}$ ). The total ${ }^{3} \mathrm{H}$ methyl thymidine incorporated in each fraction was determined by scintillation counting (Beckman Instruments, Model 3801).

\section{Plasmid isolation and quantitation}

Unlabelled cells containing the plasmids of interest were added to each fraction from the membrane-elution experiment in order to visualize the DNA on the agarose gels. A constant volume of cells containing the experimental plasmids, which had 
been labelled overnight with ${ }^{14} \mathrm{C}$-thymine ( $\left.54 \mathrm{mCi} / \mathrm{mmole}, 0.25 \mu \mathrm{Ci} / \mathrm{mi}^{\prime}\right)$ and deoxyadenosine $(100 \mu \mathrm{g} / \mathrm{ml})\left(O^{\prime}\right.$ Donovan, 1978), was added to each fraction from the membrane-elution experiment in order to correct for any DNA losses during the isolation procedure. (The amount of ${ }^{14} \mathrm{C}$-labelled cells added to the membrane-elution fractions was calculated so that the ${ }^{3} \mathrm{H} /{ }^{1.4} \mathrm{C}$ ratio was approximately unity). The combined cells ('H-labelled cells eluted from the membrane-elution apparatus, unlabelled cells, and ${ }^{14} \mathrm{C}$-labelled cells) were centrifuged at $5000 \mathrm{~g}$ for 15 minutes, resuspended in $1.5 \mathrm{ml}$ of $\mathrm{C}$ medium, and transferred to microcentrifuge tubes. The plasmids were isolated using an alkalinedetergent procedure (Maniatis et al., 1982). The resulting DNA pellets were dissolved in $20 \mu \mathrm{l}$ of TE buffer (10 mM Tris-HCl pH 8.0, 1 mM EDTA). The plasmids were separated by gel electrophoresis on a $0.5 \%$ agarose gel run at $2 \mathrm{~V} / \mathrm{cm}$ in TBE buffer ( $54 \mathrm{~g}, \mathrm{i}$ Tris-base, $0.001 \mathrm{M}$ EDTA, $27.5 \mathrm{~g} / \mathrm{l}$ beric acid) for $24 \mathrm{~h}$. The relevant plasmid bands were observed by ethidium bromide staining and UV fluorescence. The bands corresponding to the pMF26 or pBR322 plasmid, the minichromosome and the miniF plasmid were sliced from the gel, dissolved in $10 \mu \mathrm{l}$ of $70 \% \mathrm{HClO}_{4}$ at $70^{\circ} \mathrm{C}$ for $20 \mathrm{~min}$, and counted by liquid scintiliation. Plasmid replication during the division cycle was determined by dividing the relative radioactivity incorporated into plasmid DNA isolated from each membrane-elution fraction by the cell number in each fraction, i.e. $\left({ }^{3} \mathrm{H}-\mathrm{DPM} /{ }^{14} \mathrm{C}\right.$ DPM)/cell. A slice of gel of equivalent size was removed above or below the DNA band of interest and counted by liquid scintillation. The counts in these background slices were subtracted from the counts in the plasmid bands to correct for chromosomal contamination in the plasmid bands. Control experiments have shown that the radioactivity in this area below each band is an accurate and reproducible measure of the amount of chromosomal contamination present in the plasmid fragment band. This correction is relatively small and the conclusions could be made without any background correction. Control experiments also indicated that plasmid isolation was reproducible and consistent.

\section{Analysis of membrane-elution experiments}

Three types of controls were introduced to ensure accurate determination of the plasmid replication pattern during the division cycle. First, scintillation counting of the radioactivity incorporated into the plasmids allows for correction of chromosomal contamination in the plasmid bands by determining the radioactivity in interband regions. Second, addition of an equal amount of ${ }^{14} \mathrm{C}$-labelled cells to each fraction controls the recovery of plasmid at all steps of the isolation procedure. Third, the use of an in- ternal, negative control plasmid (plasmid pMF26 or plasmid pBR322) that replicates randomly during the c.ll cycle (Keasling et al., 1992a) allows one to correct for other variations during the division cycle.

\section{RESULTS}

\section{1) Replication of the mini-F plasmid pML31 is cell-cycle-specific}

Replication of the mini-F plasmid pML31 and the minichromosome pAL70 as a function of cell age was examined in $E$. coli $\mathrm{B} / \mathrm{r}$ F44 (pML31 pAL70) lising the membrane-elution technique to label cells at various ages. The plasmids were isolated from each fraction of newborn cells eluted from the membrane and separated using agarose gel elecirophoresis. The bands were cut from the gel and counted using liquid scintillation. Similar slices of agarose were cut below the plasmid bands of interest and counted using licuid scintillation; these counts were subtracted from the radioactivity in the plasmid bands to correct for chromosomal contamination. The results of one of many consistent experiments are shown in figure $i$. The data for radioactivity per ce!l incorporated into the minichromosome show a peak occurring at the midpoint of the decline of total radioactivitv incorporated per cell, indicating that the minichromosome replicates similtaneously with initiation of chromosome replication (Leonard and Helmstetter, i986). The peaked pattern in the data for radioactivity per cell incorporated into the mini-F plasmid indicates that replication is cell-cycle specific, occurring at the same time during the division cycle as the F plasmid (Keasling et al., 1991).

To confirm this result, we examined the replication pattern of the mini-F plasmid pML31 coexisting in the same cell with the minichromosome pAL70 and the high-copy plasmid pMF26 (fig. 2a). The data for radioactivity per cell incorporated into pMF26 fall on a straight line, indicating that this plasmid replicates throughout the division cyc!e and confirm earlier findings of Keasling et al. (1992a). The data for radioactivity per cell incorporated into the mini$F$ plasmid pML31 and the minichromosome 
pAL70 have peaked patterns, indicating that replication is cell-cycie specific. This result localizes cell-cycle-specific replication on the EcoR1 f5 fragment containing the oriV and oriS origins of replication and confirms the results for the native $\mathrm{F}$ plasmid. This experiment indicates

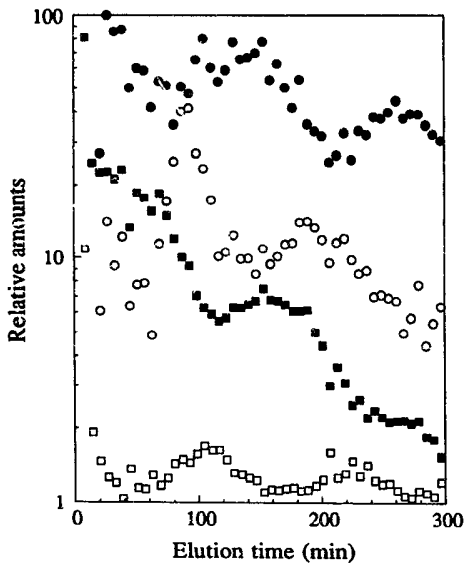

Fig. 1. Replication of mini-F piasmid pML31 and minichromosome pAL70 during the $E$. coli division cycle.

$E$. coli $\mathrm{B} / \mathrm{r} \mathrm{F} 44$ (pML31 pAL70) was grown in succinate minimal $C$ medium to exponential phase $\left(1 \times 10^{8}\right.$ cells/ml), pulse-labelled with ${ }^{3} \mathrm{H}$-methyl thymidine, and analysed using the membrane-elution technique. A $1.0-\mathrm{ml}$ sample of the same strain labelled overnight with ${ }^{14} \mathrm{C}$ thymine and a $4.0-\mathrm{ml}$ sample of the same strain grown overnight without label were added to each fraction of cells eluted from the membrane. The plasmids were isolated, separated by gel electrophoresis, removed from the gel, and counted using liquid scintillation. The open squares represent cells $/ \mathrm{ml}$ eluted from the membrane; the filled squares represent total radioactivity incorporated per cell (no TCA treatment is required since the cells collected from the membrane have been growing for long periods of time without label and so pools are absent), the open circles represent radioactivity/cell incorporated into the minichromosome pAL70, and the filled circles represent radioactivity/cell incorporated into the mini-F plasmid pML31. The minichromosome replicates wher the chromosome initiates replication at 100 and 200 minutes of elution. The mini-F plasmid pML31 replicates at 150 and 250 min of elution. that the presence of the randomly replicating pMF26 does not affect the cell-cycle-specific pattern of pAL70 and pML31.

One can often correct for unexpected variations during the division cycle or problems with the membrane-elution apparatus by plotting the data for the cell-cycle-specific control (minichromosome) and the unknown plasmid (pML31 or pMF21) relative to the data for the cell-cycle-independent control (pMF26 or pBR322). The data for pAL70 and pML31 divided by the data for pMF26 are shown in fig. $2 b$. This transformation of the data also allows one to easily compare data of a particular plasmid over several generations, since the magnitudes of the peaks and troughs of cell-cycle-specific replication are roughly the same. The data presented in figure $2 b$ indicate that plasmid pML31 and minichromosome pAL70 have a similar degree of cell-cycle specificity, i.e. the magnitudes of the differences between the peak and trough values for the plasmids are similar.

\section{2) Replication of the mini-F plasmid pMF21 is not cell-cycle-specific}

The mini-F plasmid pMF21 has been deleted for the region of the $F$ plasmid containing the oriV origin of replication (Manis \& Kline, 1978), thereby allowing us to study replication initiated from oriS. The replication patterns of the mini-F plasmid pMF21, the mini-chromosome pAL70, and the high-copy plasmid pBR322 as a function of the cell age were studied in $E$. coli B/r F44 (pMF21 pAL70 pBR322) using the same methods as for the analysis of pML31 (fig. 3). The data for radioactivity per cell incorporated into the mini-F plasmid pMF21 and the minichromosome pAL70 have been corrected for loss during isolation and purification, corrected for chromosomal contamination, and normalized to radioactivity per cell incorporated into pBR322. The data for radioactivity per cell incorporated into the pBR322 plasmid fall on a straight line (data not shown) indicating that replication is cell-cycle-independent and confirming the results of Zeuthen et al. (1972) and Leonard and Helmstetter (1988). Peaks appear in the minichromo- 
some data indicating that replication is cell-cyciespecific. In contrast, the mini-F plasmid (pMF21) data sł.ow no consistent and clear peaked pattern.

\section{3) Copy number of mini-F plasmids}

The relative copy numbers of the pMF21 and pML31 plasmids were determined by integrating (over 1 generation of cells eluted from the membrane) the amount of radioactivity per cell
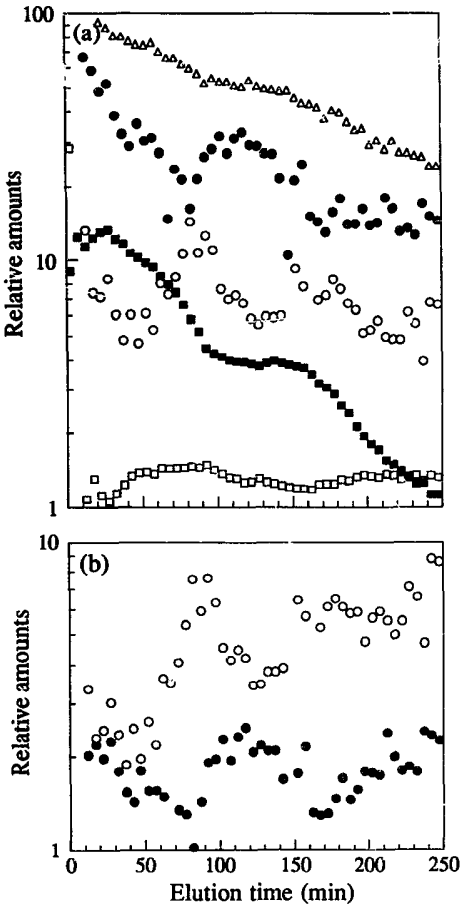

incorporated into the mini-F plasmids relative to the total radioaci ivity incorporated per iell (cssentialiy the amount of radioactivity incorporated into the chromosome). We find that the copy number of the pMF21 plasmid is approximately twice that of the pML31 plasmid.

\section{DISCUSSION}

In earlier work, we showed that replication of the F plasmid is cell-cycle-specific, and that

Fig. 2. Replication oî mini-F plasmid pML31, minichromosome $\mathrm{pAL} 70$, and plasmid pMF26 during the E. coli divisioni cycle.

E. coli B/r F44 (pML31 pAL70 prif26) was grown in succinate minimal $C$ medium to exponential phase $\left(1 \times 10^{8}\right.$ cells $/ \mathrm{ml}$ ), pulse-labelied with ' $\mathrm{H}$-methyl :hymidine, and analysed using the membrane-elution technique. A $1.0 \mathrm{ml}$ sample of the same strain labelled overnight with ${ }^{14} \mathrm{C}$ thymine and a $4.0 \mathrm{ml}$ sample of the same strair. grown overnight without label were added to each fraction of cells eluted from the membrane. The plasmids were isolated, separated by gel electrophoresis, removed from the gel, and counted using riquid scintillation. (a) The open squares represent ceils/ml from the membrane, the filled sipuares represent total radioactivity incorporated per cell, thi open circles represent radioactivity/cell incorporated into minichromosome pAL70, the filled circles represent radioactivity/cell incorporated into mini-F plasmid pML31, and the open triangles represent radioactivity/cell incorporated into plasmid pMF26. The minichromosome replicates when the chromosome initiates replication at 75 and 175 min of elution. The mini-F plasmid pML31 replicates at 10,120 , and 230 minutes of elution. (b) The open circles represen: radioactivity/cell incorporated into minichromosome pAL 70 divided by the radioactivity/cell incorporated into plasmid pMF26, and the filled circles represent radioactivity/cell incorporated into mini-F plasmid pML 31 divided by the radioactivity/cell incorporated into plasmid pMF26. 


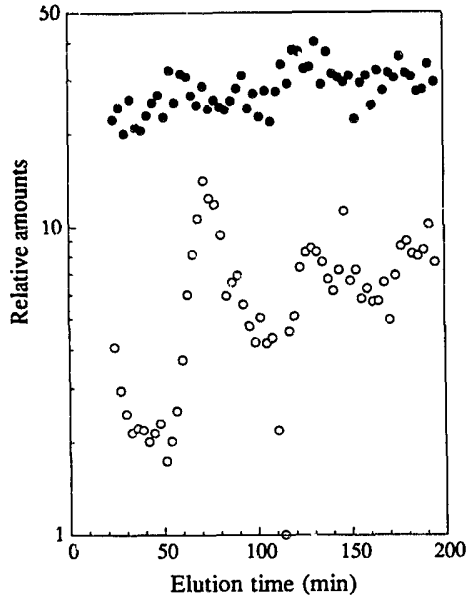

Fig. 3. Replication of mini-F plasmid pMF21, minichromosome pAL70, and plasmid pBR322 during the E. coli divisicn cycle.

E. coli 3/r F44 (pMF21 pAL70 pBR322) was grown in succinate minima! $C$ medium to exponential phase $\left(1 \times 10^{8} \mathrm{cells} / \mathrm{ml}\right)$, pulse-labelled with ${ }^{3} \mathrm{H}$-methyl thymidine, and analysed using the memorane-elution technique. A $1.0-\mathrm{ml}$ sample of the same strain labelled overnight with ${ }^{14} \mathrm{C}$-thymine and a $4.0-\mathrm{ml}$ semple of the same strain grown overnight withant labei were added to each fraction of cells eluted from the membrane. The plasmids were isolated, separated by ge! electrophoresis, removed from the gel and counted using liquid scintillation. The open circles represent radioactivity/cell incorporated into minichromosome pAL70 divided by the radioactivity/cell incorporated into plasmid $\supset B R 322$, and the filled circles represent radioactivity/cei: incorporated into mini-F plasmid pMF21 divided by the radioactivity/cell incorporated into plasmid pBR322. No peaked pattern can be seen in the data for the mini-F plasmid.

initiation occurs when a constant mass per origin is achieved (Keasling et al., 1991). Since three origins of replication have been identified on the F plasmid, we investigated which origin, combination of origins, or any other element is responsible for cell-cycle-specific replication.
Mini-F plasmids containing one or two replication origins were used to successively localize fragments or parts of the F plasmid that do not contribute to cell-cycle-specific replication.

The mini-F plasmid pML31 (f5 EcoR1 fragment of $\mathrm{F}$ with $\mathrm{kan}^{\prime}$ ) contains two of three possible replication origins. Our results indicate that the mini-F plasmid pML31 replicates in a cellcycle-specific manner with a pattern and cellcycle timing similar to the parental $F$ plasmid. We suggest that some element located on the f5 $E c o R 1$ fragment is sufficient for cell-cyclespecific replication of plasmid $F$. That the replication origin on the 7 EcoR 1 fragment of the F plasmid is not necessary for cell-cycle replication agrees with earlier findings that this origin only governs replication when the two origins of the f5 EcoR 1 fragment have been inactivated (Lane, 1981).

The mini-F plasmid pMF21 is plasmidpML31-deleted for the BamHI-BamHI region between 40.8 and $43.0 \mathrm{~kb}$ of the $F$ plasmid containing the oriV replication origin. Our results indicate that the mini-F plasmid pMF21 replicates randomly throughout the division cycle. This finding is similar to the results of Leonard and Helmstetter (1988), and suggests that some element within this region, possibly ori $V$, may be required for cell-cycle-specific $F$ piasmid replication. Kline (1985) has speculated on possible interactions between ori $V$ and oriS through plasmid-encoded protein:. The BamHIBam HI fragment removed from pML31 to make pMF21 contains the oriV replication origin, as well as the pifC and pif $A$ genes. The loss of this fragment results in the loss of pifC and pif $A$ gene products and the loss of pifO (operator) function (Miller and Malamy, 1984). Since the pifC gene product is necessary for replication from ori $V$, it is possible that both pifC and oriV are necessary for cell-cycle-specific $F$ plasmid replication. At this time, we ars unable to determine if the oriV origin is sufficient for cell-cyclespecific replication; the origin has been isolated only as a pBR322:F construct deleted for the oriS origin of replication (Tanimoro and lino, 1984,1985 ) but not as an independently replicating plasmid. Our results are supported by the 
reports that the replication of the $F$ plasmid and the mini-F plasmid pML31 are similar, and that the replication properties of the mini-F plasmid pMF21 differ fron those of the mini-F plasmid pML31 and the F plasmid (Shields et al., 1987).

Differences in the replication patterns of $\mathrm{criV}$ and $o r i S$ may explain, in part, the different patterns found for the $F^{\prime}$ lac plasmid over the past twenty years (Andresdottir and Masters, 1978; Collins and Pritchard, 1973; Cooper, 1972; Davis and Helmstetter, 1973; Fin icelstein and Helmstetter, 1977; Keasling et al., 1991 ; Leonard and Helmstetter, 1988; Nishi and Horiuchi, 1966; Pritchard et al., 1975; Steinberg and Helmsietter, 1981 ; Zeuthen and Pato, 1971). Any mutation inactivating ori $V$ would result in random replication from the oriS origin of replication. Also, it seems possible that different origins could predominate under different conditions, as all three origins remain intact and functional on the plasmid. Unfortunately, many of the observed differences in $\mathrm{F}$ piasmid replication patterns may also be due to experimental differences (see Keasling et al. (1991) for a discussion). The similar replication patterns of the $\mathrm{F}^{\prime}$ lac plasmid and the mini-F plasmid pML31 support our previous results (Keasling et al., 1991) that $F$ plasmid replication is cell-cycle-specific.

\section{Acknowledgements}

This work was supported by a grant from the Biomedical Research Committee of the University of Michigan Medical School, by the Presidential Initiatives Fund of the University of Michigan, and the National Institutes of Health Grant R01 GM44022-01A1.

\section{Réplication de mini-plasmides $F$ au cours du cycle de division bactérienne}

Les modèles de réplication de deux mini-plasmides F au cours du cycle cellulaire ont été examinés à l'aide d'une technique d'élution de la membrane (dans le but de produire des cellules marquées à différents moments au cours du cycle de division) et d'un comptage de scintillation (pou, l'analyse quantitative de la radioactivité incorporée dans l'ADN plasmidique).

Le mini-plasmide F, pML31, contenant les origines de réplication oriV et oriS, se réplique d'une façon qui est spécifique au cycle cellulaire, avec ie modèle et le "timing" du cycle cellulair $t$ semblables à ceux du plasmide parental $F$. Le mini-plasmide $F$, pMF21, ayant une délétion dans la région contenant l'origine de réplication! oriV, se réplique plus au hasard à travers le cycle de division. Ces résultats suggèrent que l'origine de replication oriV pourrait être liée à la réplication spécifique du cycle ceilulaire du plasmide $\mathrm{F}$.

Mots-clés: Plasmide, Cycle cellulaire, Plasmide F, Réplication; Origines, Escherichia coli.

\section{References}

Andresdottir, V. \& Masters, M. (1978), Evidence that $F^{\prime} l a c$ replicates asynchronously during the cell cycle of Escherichia coli B/r. Mol. Gen. Genetics, 163, 205-212.

Collins, J. \& Pritchard, R.H. (1973), Relationship between chromosome replication and $\mathrm{F}^{\prime} / a c$ replication in Escherichia coli. J. mol. Biol., 78, 143-155.

Cooper, S. (1972), Relationship of F'lac replication and chromosome replication. Proc. nat. Acad. Sci. (Wash.), 69, 2906-2710.

Davis, D.B. \& Heimstetter, C.E. (1973), Control of F'lac replication in Escherichia coli B/ז. J. Bact., 114, 294-299.

Eichenlaub, R., igurski, D. \& Helinski, D.R. (1977), Bidirectional replication from a unique origin in a miniF plasmid. Proc. nat. Acad. Sci. (Wash.), 74, 1138-1141.

Eichenlaub, R., Wehlmann, H. \& Ebbers, J. (1981), Plasmid mini-F-encoded functions involted in replication and incomnatibility, in "iviolecular biology, pathogenicity, and ecology of bacterial plasmids" (S. B. Levy, R.C. Clowes \& E.L. Koenig) (pp. 327-336). Plenum Press, New York.

Finkelstein, M. \& Helmstetter, C.E. (1977), Cell cycle analysis of F'lac replication in Eschericha coli. J. Bact., $132,884-895$.

Helmstetter, C.E. \& Cooper, S. (1968), DNA synthesis during the division cycle of rapidly growing Escherichio coli B/r. J. mol. Biol., 31, 507-510.

ňeasling, J.D., Palsson, B.O. \& Cuoper, S. (1991), Cellcycle-specific $F$ plasmid replication : regulation by cell size control of initiation. J. Bact., 173, 2673-2680.

Keasling, J.D., Palsson, B.O. \& Cooper, S. (1992a), Replication of the R6K plasmid during the Escherichia coli cell cycle. $J$. Bact., 174, 1060-1062.

Keas'ing, J.D., Palsson, B.O. \& Cooper, S. (1992b), Replication of prophage $\mathrm{Pl}$ is cell-cycle specific. $J$. Bact. $174,4457-4462$.

Kline, B.C. (1985), A review of mini-F plasmid maintenance. Plasmid, 14, 1-16.

Ḱoppes, 1.J.H. (1992), Nonrandom F-plasmid replication in Escherichia coli K-12, J. Bact., 174, 2121-2!23.

Lane, H.E.D. (1981), Replication and incompatibility of $\mathrm{F}$ and plasmids in the IncRI group. Plasmid, 5, $100-126$. 
Leonard, A.C. \& Helmstetter, C.E. (1986), Cell cyclespecific replication of Escherichia coli minichromosomes. Proc. nat. Acad. Sci. (Wash.), 83, 5101-5105.

Leonärd, A.C. \& I Ieliüstititer, C.E. (1988), Replication patterns of multiple plasmids coevisting in Escherichia coli. J. Bact., 170, 1380-1383.

Loveit, M.A. \& Helinski, D.R. (1976), Method for the isolation of the replication region of a bacterial replicon: construction of a mini-F' $\mathrm{km}$ plasmid. J. Bact., 127. 982-987.

Maniatis, T., Fritsch, E.F. \& Sambrock, J. (1982), Molecular Cloning (a Laboratsi y Manual). Cold Spring Harbor Laboratory, New York.

Manis, J. \& Kline, B. (1978), Recombination between an $\mathrm{F}^{\prime} / \mathrm{ac}$ and a mini- $\mathrm{FKm}$ plasmid deleted for an origin of repiication. Plasmid, 1, 480-491.

Miller, J.F. \& Malamy, M.H. (1984), Regulation of the F-factor pif opuron: pifo, a site required in cis for autoregulition titrates the pifC product in trans. $J$. Boct. 160, 192-198.

Nishi, A. \& Horiuchi, T. (1966), ß-galactosidase formation controlled by an opisomal gene during the cell cycle of Escherichia coli. J. Biochem. (Tokyc), 60, 338-340.

O'Donovan, G.A. (1978), Thymidine metabolism in bacteria, in "DNA synthesis. Present and future" (Molineux, I. \& Kohiyama, M.) (pp. 219-253). Plenum Press, New York.

Pritchard, R.H., Chandier, M.G. \& Collins, J. (1975), Inuspendence of $F$ repiication and chromosomal repli- cation in Escherichia coli. Mol. Gen. Genetics, 138, 143-155.

Shields, M.S., Kline, B.C. \& Tam, J.E. (1987), Similarities in control of mini-F plasmid and chromosomal replication in Escherichia coli. J. Batit, 169, 3375-3378.

Steinberg, D.A. \& Helmstetter, C.E. (1981), F plasnid replication and the division cycle of Escherichia ccli $\mathrm{B} / \mathrm{r}$. Plasmid, 6, 342-353.

Tanimoto, K. \& lino, T. (1984), Ar essential gene for replication of the mini-F plasmid from origin I. Mol. gen. Genetics, 196, 59-63.

Tanimoto, K. \& Iino, T. (1985), Additional genes essential for replication of the mini-F plasmid from origin I. Mol. gen. Genetics, 198, 358-359.

Timmis, K., Cabello, F. \& Cohen, S.N. (1975), Cloning, isolation, and characterization of repiication regions of complex plasmid genomes. Proc. nat. Acad. Sci. (Wash.), 72, 2242-2246.

Wada, C., Imai, M. \& Yura, T. (1987), Host control of plasmid replication: requirement for the sigma factor sigma 32 in transcription of mini-F replication initiator genc. Proc. nat. Acad. Sci. (Wash.), 84, 8849-8853.

Zeuthen, J., Morozow, E. \& Pato, M.L. (1972), Pattern of replication of a colicin factor during the cell cycle of Escherichia coli. J. Bact., 112, 1425-1427.

Zeuthen, J. \& Pato, M.L. (1971), Replication of the F'lac sex factor in the cell cycle of Escherichia coli. Mol. gen. Genetics, i11, 242-25s. 